\title{
Histopathological Pattern of Endometrium in Menopausal Women with Postmenopausal Bleeding
}

Dr. Joysree Saha ${ }^{1 *}$, Dr. Indrajit Prasad ${ }^{2}$, Dr. Sohana Siddique ${ }^{3}$, Dr. Sumaya Akter ${ }^{4}$, Dr. Md. Mostafizur Rahman ${ }^{5}$, Dr. Shabnam Imam $^{6}$, Dr. Kohinoor Begum ${ }^{7}$

${ }^{1}$ Associate Professor, Department of Gynecology \& Obstetrics, Popular Medical College, Dhaka, Bangladesh

${ }^{2}$ Associate Professor, Department of Endocrinology, Dhaka Medical College, Dhaka, Bangladesh

${ }^{3}$ Associate Professor, Department of Gynecology \& Obstetrics, International Medical College, Gazipur, Bangladesh

${ }^{4}$ Department of Gynecology \& Obstetrics, Popular Medical College, Dhaka, Bangladesh

${ }^{5}$ Associate Professor, Department of Pathology, Popular Medical College, Dhaka, Bangladesh

${ }^{6}$ Associate Professor, Department of Community Medicine, Bangladesh Medical College, Dhaka, Bangladesh

${ }^{7}$ Professor, Department of Gynecology \& Obstetrics, Popular Medical College, Dhaka, Bangladesh

*Corresponding author: Dr. Joysree Saha

\section{Abstract}

Background: Postmenopausal bleeding is generally regarded as an ominous and serious alarm of genital pathologies; represents $5 \%$ of all gynecological visits. To develop the treatment procedure of postmenopausal bleeding and to increase the success rate of such treatment, knowledge on the histopathological pattern of endometrium in menopausal women with postmenopausal bleeding is very essential. Aim of the study: The aim of the study was to evaluate various causes of postmenopausal bleeding based on histopathology, and the percentage of various benign, premalignant and malignant endometrial and cervical lesions. Materials and Methods: This was a cross-sectional analytical study which was conducted at OPD, Department of Gynecology and Obstetrics, Popular Medical College, Dhaka, Bangladesh during the period from January 2018 to December 2018. In total 45 menopausal women diagnosed as patients among them 31 patients with postmenopausal bleeding were selected as the study population. Ethical clearance had been taken from the ethical committee of the medical college. All data were processed, analyzed, and disseminated by MS Office and SPSS version 20 as per need. Result: In this study according to the diagnosis report, we found the highest number of participants were with an endometrial polyp and/or chronic cervicitis which was $22.56 \%$ separately. No malignancy was seen among $19.35 \%$, Besides these, squamous metaplasia was $19.35 \%$, endometrial adenocarcinoma $9.68 \%$, endometrial hyperplasia with atypia $6.45 \%$, endometrial hyperplasia without atypia $6.45 \%$, papillary adenocarcinoma $3.23 \%$ and finally smile cystic change of endometrium 3.23\%. Conclusion: Endometrial polyp, no malignancy, endometrial adenocarcinoma, and chronic cervicitis are the most potential endometrial characteristics of menopausal women with postmenopausal bleeding. On the other hand, abdominal pain is the most potential associated symptom of patients with postmenopausal bleeding.

Keywords: Menopause, reproductive health, postmenopausal bleeding, endometrial carcinoma.

Copyright ( $) 2021$ The Author(s): This is an open-access article distributed under the terms of the Creative Commons Attribution 4.0 International License (CC BY-NC 4.0) which permits unrestricted use, distribution, and reproduction in any medium for non-commercial use provided the original author and source are credited.

\section{INTRODUCTION}

Menopause is a physiological event occurring in women at the age of on an average 50. Basically, the approximate age of menopause is $49 \pm 3.6$ years. It signals the end of reproductive years and is associated with signs of estrogen deficiency, and has a considerable impact on women's health related quality of life. Menopause is derived from the Greek word 'meno' (month) and pause to stop [1]. Post-menopausal bleeding is generally regarded as an ominous and serious alarm of genital pathologies. Menopausal bleeding is defined as "Bleeding through the female genital tract, 12 months after the cessation of menstrual cycles (menopause) [1]." It is a manifestation of the diverse disease accounting for 5-10\% of the gynecology clinic visits [2]. It may be heavy bleeding, spotting, or just normal menstruation. Postmenopausal bleeding occurs over a wide range and can result from a number of pathologies arising in any of the female genital tract 
Joysree Saha et al; Sch Int J Obstet Gynec, Feb. 2021; 4(2): 24-28

organs, particularly the uterus and cervix [3]. PMB can result from the normal physiologic atrophic changes, infections, benign lesions such as polyps, hyperplastic (pre-malignant) conditions, and aggressive malignant conditions. A number of systemic disorders, especially blood dyscrasias are also associated with this symptom [4-6]. In this era, trends in life expectancy show that women are living longer and many will experience the postmenopausal phase. In this age group, genital tract bleeding is an alarming symptom. The dictum is "postmenopausal bleeding indicates malignancy until proved otherwise". However, they have a right to live a long life in good health, rather than one of pain and misery due to malignancy [7-9]. The incidence of carcinoma cervix has fallen in the developed countries significantly due to regular screening programs and subsequent detection at an early level. Similarly, due to high public awareness about the signs and symptoms of carcinoma endometrial, women with PMB have early visits and detection at the initial stage [10-12]. Because of lack of screening programs, poverty, lack of health facilities, and high illiteracy rate in our country, this symptom is usually ignored along with other medical problems, and women present at a very late stage. Moreover, the adoption of urban lifestyle has led to an increase in obesity, hypertension, and diabetes mellitus in our population which is known risk factors for endometrial cancer [14]. Therefore, these disease threatening medical situation demands the estimation of recent burden.

Current guidelines mandate immediate clinical evaluation and Trans-Vaginal Ultrasound (TVS) assessment followed by D \& C or hysteroscopy guided endometrial/endocervical biopsy and subsequent histological evaluation [15]. The current study was carried out to evaluate various causes of postmenopausal bleeding based on histopathology, and the percentage of various benign, premalignant and malignant endometrial and cervical lesions in postmenopausal bleeding.

\section{OBJECTIVES}

\section{General Objective}

- To collect information regarding the histopathological etiology of endometrium in women with postmenopausal bleeding.

\section{Specific Objective}

- To collect information regarding sociodemographic status of women with postmenopausal bleeding.

- To collect information regarding the associated symptoms of women with postmenopausal bleeding.

\section{METHODOLOGY \& MATERIALS}

This was a cross-sectional analytical study which was conducted at OPD of the Department of Gynecology and Obstetrics of Popular Medical College, Dhaka, Bangladesh during the period from January 2018 to December 2018. Out of total 45 menopausal women diagnosed as patients 31 with postmenopausal bleeding were selected as the study population. Ethical clearance had been taken from the ethical committee of the medical college. According to the exclusion criteria of the study mentally ill and unable to answer the question and patients with other chronic diseases were excluded from the study. The sample was selected conveniently to interview the study population considering the inclusion and exclusion criteria. The sample size was selected by convenient sampling technique. The statistical analysis of the data was carried out by using the software program SPSS version 20. For summarizing data, statistics such as mean, median, mode and percentage were calculated. The data were presented in several tables.

\section{RESULT}

In this study, the mean $( \pm \mathrm{SD})$ age of the participants was $61.32 \pm 9.76$ years. The mean $( \pm \mathrm{SD})$ menarche and the mean $( \pm \mathrm{SD})$ postmenopausal period were $13.58 \pm 1.71$ year and $14.16 \pm 11.59$ month respectively. Among total participants $6.5 \%$ was $24-50$ years, $58.1 \%$ was $51-60$ years, $12.8 \%$ was $61-70$ years and $22.6 \%$ of patients were from $>70$ years' age groups. According to the marital status of the participants, $6.5 \%$ were single, $67.7 \%$ were married and, $25.8 \%$ were widowed. According to the occupational status of the participants, $90.3 \%$ was housewife, $6.5 \%$ patients was service holder and $3.2 \%$ was self-employed. According to the social status of the participants $3.2 \%, 71 \%$, and $25.8 \%$ of patients were from the lower, middle, and higher classes respectively. In total $77.4 \%$ of participants were educated whereas $22.6 \%$ were illiterate. According to the number of children of the participants we observed $12.8 \%$ had one, $22.6 \%$ had two, $58.1 \%$ had more than two, and $6.5 \%$ had no children respectively. Besides postmenopausal bleeding abdominal pain $80.65 \%$, white discharge $25.81 \%$, backache was found $22.58 \%$ as some potential associated symptoms in the participants. In this study, according to the diagnostic report, we found the highest number of participants were with an endometrial polyp and/or chronic cervicitis which was $22.58 \%$ separately. No malignancy was seen among $19.35 \%$. Besides these squamous metaplasia $6.45 \%$, endometrial adenocarcinoma $9.68 \%$, endometrial hyperplasia with atypia $6.45 \%$, endometrial hyperplasia without atypia $6.45 \%$, papillary adenocarcinoma $3.23 \%$, simple cystic change of endometrium $3.23 \%$ among the participants. 
Table-1: Socio-demographic status of participants $(n=31)$

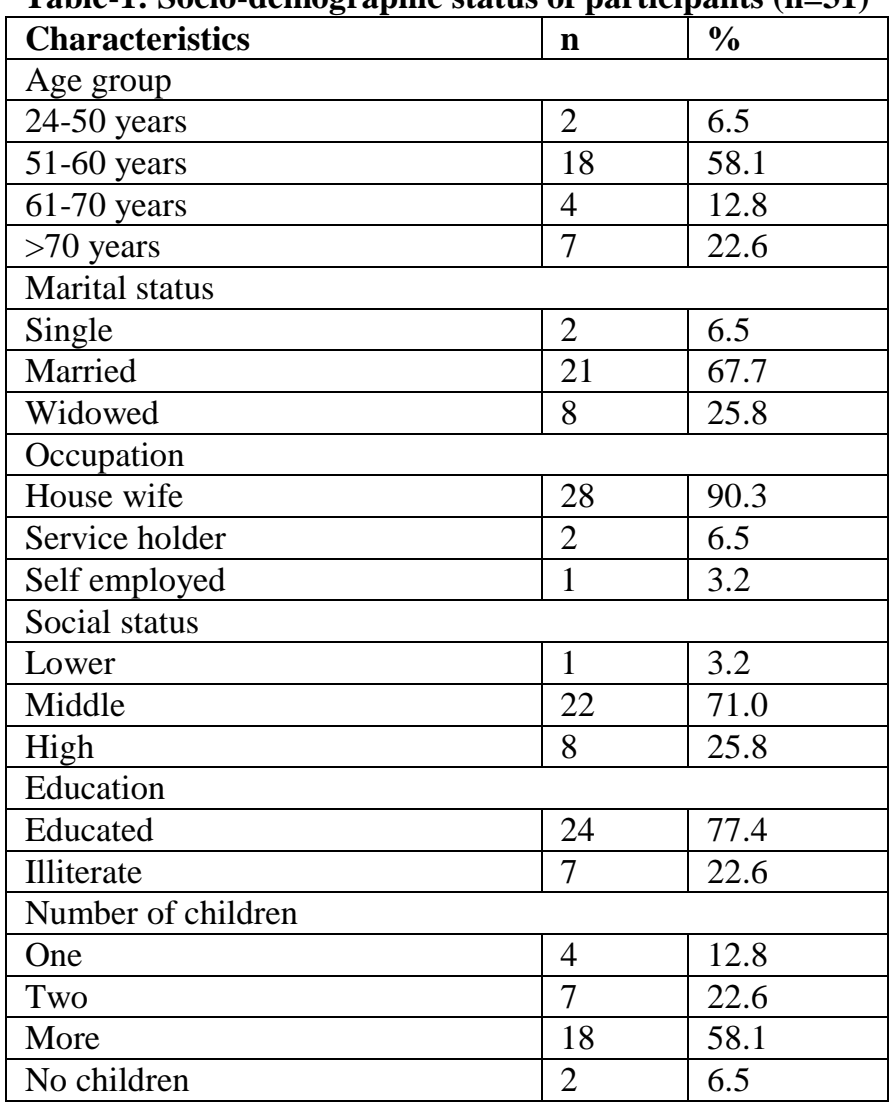

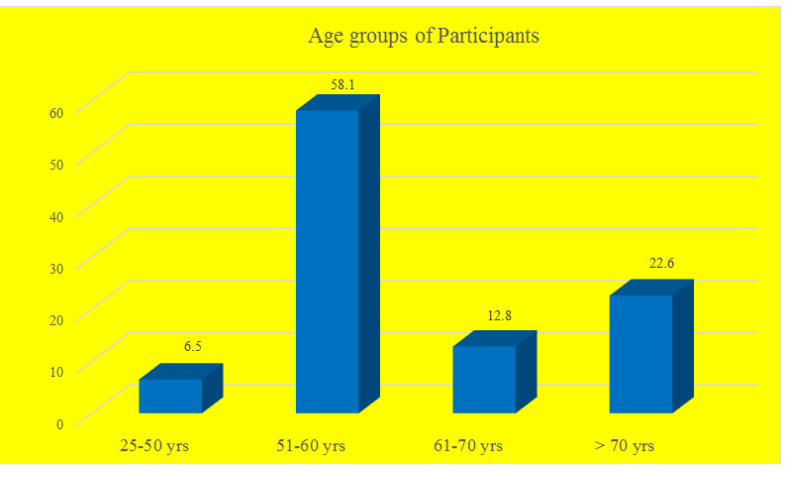

Fig-1: Age group of Participants

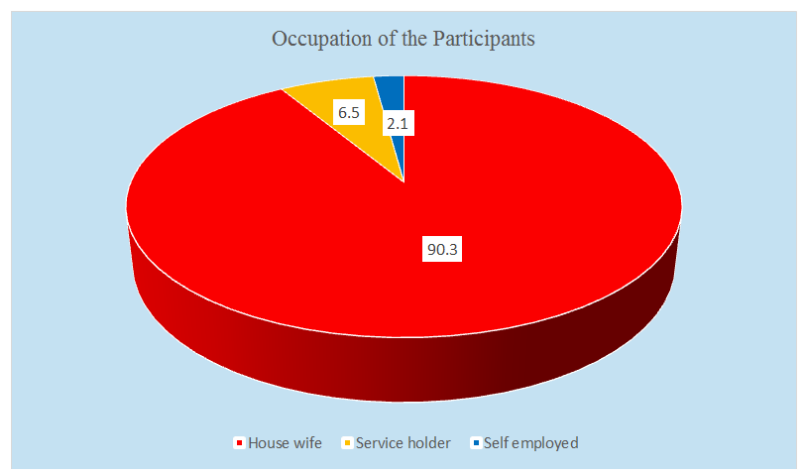

Fig-2: Occupation of Participants

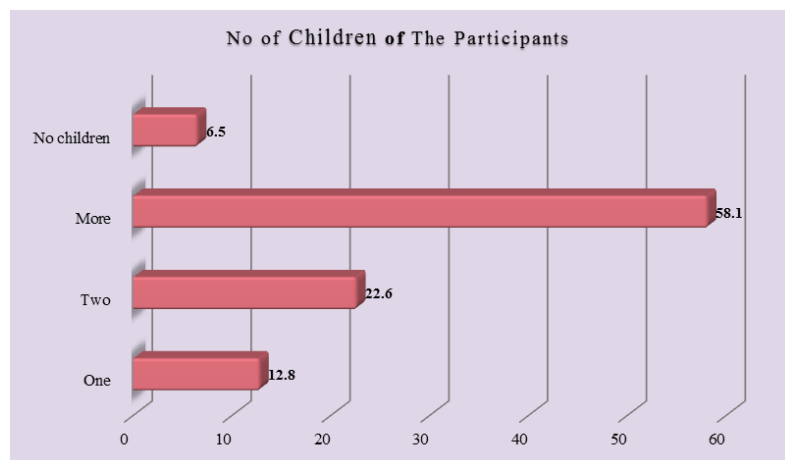

Fig-3: Number of Children of the Participants

Table-2: Endometrial patterns of participants as per diagnosis $(n=31)$

\begin{tabular}{|l|l|l|}
\hline Characteristics & $\mathbf{n}$ & $\mathbf{\%}$ \\
\hline Endometrial polyp & 7 & 22.58 \\
\hline No malignancy seen & 6 & 19.35 \\
\hline Squamous metaplasia & 2 & 6.45 \\
\hline Endometrial Adenocarcinoma & 3 & 9.68 \\
\hline Endometrial hyperplasia with atypia & 2 & 6.45 \\
\hline Endometrial hyperplasia without atypia & 2 & 6.45 \\
\hline Papillary adenocarcinoma & 1 & 3.23 \\
\hline Simple cystic change of endometrium & 1 & 3.23 \\
\hline Chronic Cervicitis & 7 & 22.58 \\
\hline
\end{tabular}


Joysree Saha et al; Sch Int J Obstet Gynec, Feb. 2021; 4(2): 24-28

Table-3: Endometrial patterns of participants as per diagnosis $(\mathbf{n}=31)$

\begin{tabular}{|l|l|l|}
\hline Associated symptoms & n & \% \\
\hline Abdominal pain & 25 & 80.65 \\
\hline White discharge & 8 & 25.81 \\
\hline Backache & 7 & 22.58 \\
\hline
\end{tabular}

\section{DISCUSSION}

The aim of the study was to evaluate various causes of postmenopausal bleeding based on histopathology, and the percentage of various benign, premalignant and malignant endometrial and cervical lesions. Postmenopausal bleeding is frequent in gynecology and accounts for approximately 3\% of postmenopausal women [10]. This symptom can reveal benign causes as well as cancers. The risk of endometrial carcinoma in women with postmenopausal bleeding rises with age from $1 \%$ at the age of 50 years to approximately $25 \%$ at the age of 80 years [11]. Ages of patients with postmenopausal bleeding in the current study ranged between 24 years and 80 years with a mean age of $59.11 \pm 11.61$ years. This age is much lower than the mean age of 64 years by Kour M et al., [12] and 63.6 years by Nasira Sabiha Dawood et al., [13]. The lower mean age in our study group may be due to a higher incidence of cervical carcinoma which has an early age of presentation. It has been reported that the incidence of PMB decreases with increasing age [11]. In our study the mean $( \pm \mathrm{SD})$ age of the participants was $61.32 \pm 9.76$ years. The mean $( \pm \mathrm{SD})$ menarche and the mean $( \pm \mathrm{SD})$ postmenopausal period were $13.58 \pm 1.71$ years and $14.16 \pm 11.59$ month respectively. Among total participants, $6.5 \%$ was $24-50$ years, $58.1 \%$ was $51-60$ years, $12.8 \%$ was $61-70$ years and $22.6 \%$ of patients were from $>70$ years' age groups. But another study, Arati Mallick also proved the same. 87(62.5\%) cases of postmenopausal bleeding were between 51 and 60 years of age, while only 21 cases $(15 \%)$ were above 65 years of age $[16,17]$. In our study according to the diagnostic report we found the highest number of participants were with an endometrial polyp and/or chronic cervicitis which was found in $22.58 \%$ separately. No malignancy was seen among $19.35 \%$. Besides these squamous metaplasia $6.45 \%$, endometrial adenocarcinoma $9.68 \%$, endometrial hyperplasia with atypia $6.45 \%$, endometrial hyperplasia without atypia $6.45 \%$, papillary adenocarcinoma $3.23 \%$, and simple cystic change of endometrium $3.23 \%$ among the participants. In this study a predominant observation in women presented with PMB is endometrial atrophy (30\%), such finding is comparable to that of Bani-Irshaid et al., [18]. The cause of bleeding from an atrophic endometrium is not known but the anatomical vascular changes particularly thinning of the wall of veins lying superficial to the dilated cystic endometrial glands making the vessel more vulnerable to damage in addition to irregular local hemostatic mechanisms in the uterus [19]. Proliferative endometrium $(15 \%)$ and secretory endometrium $(5 \%)$ were identified in the postmenopausal women which is a comparable finding to other studies that reported a proliferative endometrium with dense stroma and increased extracellular matrix in the postmenopausal women under the effect of estrogen similar to the endometrium found in the premenopausal monthly cycle while progesterone induces further thickening of the endometrium, increased vascularity, large tortuous glands filled with secretions [20]. Endometrial hyperplasia was identified in $30 \%$ of the cases such finding is significant since it is considered to be a precursor of endometrial carcinoma with a wide variation in the percentage of progression according to the type of hyperplasia [21]. Simple endometrial hyperplasia without atypia found in $25 \%$ of patients which is comparable to Ellenson et al., 2010 [22] who reported that endometrial hyperplasia results from chronic estrogen stimulation unbalanced by the counter effects of progesterone and characterized by proliferation of endometrial glands. The role of progesterone is to eradicate endometrial hyperplasia. Endometrial polyps found in $5 \%$ of women, might be attributed to the difference between the endometrial polyp and normal endometrium regarding the cell proliferation, receptor expression, and apoptosis suggesting that polyp may be considered as a precancerous pathology [23].

\section{LIMITATIONS OF THE STUDY}

This was a single centered study with a small sample size. So the findings of this study may not reflect the exact scenario of the whole nation.

\section{CONCLUSION AND RECOMMENDATIONS \\ Endometrial polyp, no malignancy,} endometrial adenocarcinoma, and chronic cervicitis are the most potential endometrial characteristics of menopausal women with postmenopausal bleeding. On the other hand, abdominal pain is the most potential associated symptom of patients with postmenopausal bleeding. As there were some unavoidable limitations in this study, for getting more specific findings we would like to recommend conducting more studies regarding the same issue with the larger sample size.

\section{REFERENCES}

1. Mallick, A., Behera, R., \& Subudhi, K. (2013). Histopathological study of endometrium in postmenopausal bleeding. Journal of Evolution of Medical and Dental Sciences, 2(46), 9010-9019.

2. Sharma, S., Makaju, R., Shrestha, S., \& Shrestha, A. (2014). Histopathological findings of endometrial samples and its correlation between the premenopausal and postmenopausal women in abnormal uterine bleeding. Kathmandu University Medical Journal, 12(4), 275-278.

3. Astrup, K., \& Olivarius, N. D. F. (2004). Frequency of spontaneously occurring postmenopausal bleeding in the general 
Joysree Saha et al; Sch Int J Obstet Gynec, Feb. 2021; 4(2): 24-28

population. Acta obstetricia et gynecologica Scandinavica, 83(2), 203-207.

4. Karlsson, B., Granberg, S., Wikland, M., Ylöstalo, P., Torvid, K., Marsal, K., \& Valentin, L. (1995). Transvaginal ultrasonography of the endometrium in women with postmenopausal bleeding-a Nordic multicenter study. American journal of obstetrics and gynecology, 172(5), 1488-1494.

5. Gupta, J. K., Chien, P. F., Voit, D., Clark, T. J., \& Khan, K. S. (2002). Ultrasonographic endometrial thickness for diagnosing endometrial pathology in women with postmenopausal bleeding: a metaanalysis. Acta obstetricia et gynecologica Scandinavica, 81(9), 799-816.

6. Dijkhuizen, F. P. H., Brölmann, H. A., Potters, A. E., Bongers, M. Y., \& Heintz, A. P. M. (1996). The accuracy of transvaginal ultrasonography in the diagnosis of endometrial abnormalities. Obstetrics \& Gynecology, 87(3), 345-349.

7. Goldstein, S. R., Zeltser, I., Horan, C. K., Snyder, J. R., \& Schwartz, L. B. (1997). Ultrasonographybased triage for perimenopausal patients with abnormal uterine bleeding. American journal of obstetrics and gynecology, 177(1), 102-108.

8. Munot, S., \& Lane, G. (2008). Modern management of postmenopausal bleeding. Trends in Urology, Gynaecology \& Sexual Health, 13(5), 20-24.

9. Dueholm, M., Jensen, M. L., Laursen, H., \& Kracht, P. (2001). Can the endometrial thickness as measured by trans-vaginal sonography be used to exclude polyps or hyperplasia in premenopausal patients with abnormal uterine bleeding?. Acta obstetricia et gynecologica Scandinavica, 80(7), 645-651.

10. Ciatto, S., Cecchini, S., Gervasi, G., Landini, A., Zappa, M., \& Crocetti, E. (2002). Association of endometrial thickness assessed at trans-vaginal ultrasonography to endometrial cancer in postmenopausal women asymptomatic or with abnormal uterine bleeding. La Radiologia Medica, 104(5-6), 437-442.

11. Getpook, C., \& Wattanakumtornkul, S. (2006). Endometrial thickness screening in premenopausal women with abnormal uterine bleeding. Journal of Obstetrics and Gynaecology Research, 32(6), 588592.

12. Van den Bosch, T., Van Schoubroeck, D., Ameye, L., De Brabanter, J., Van Huffel, S., \& Timmerman, D. (2003). Ultrasound assessment of endometrial thickness and endometrial polyps in women on hormonal replacement therapy. American journal of obstetrics and gynecology, 188(5), 1249-1253.
13. Gull, B., Karlsson, B., Milsom, I., Wikland, M., \& Granberg, S. (1996). Transvaginal sonography of the endometrium in a representative sample of postmenopausal women. Ultrasound in Obstetrics and Gynecology: The Official Journal of the International Society of Ultrasound in Obstetrics and Gynecology, 7(5), 322-327.

14. Jignash, P., \& Deepak, D. (2013). Study of endometrial pathology in abnormal uterine bleeding. Int $\mathbf{J}$ Reprod Contracept Obstet Gynecol. 2(2), 182-5.

15. Ara, S., \& Roohi, M. (2011). Abnormal Uterine Bleeding: Histopathological diagnosis by conventional dilatation and curettage. Prof Med J, 18(4), 587-91.

16. Munro, M. G. (2014). Investigation of women with postmenopausal uterine bleeding: clinical practice recommendations. The Permanente Journal, 18(1), 55-70.

17. Breijer, M. C., Timmermans, A., Van Doorn, H. C., Mol, B. W. J., \& Opmeer, B. C. (2010). Diagnostic strategies for postmenopausal bleeding. Obstetrics and gynecology international, 2010. 85(10), 15-20.

18. Bani-Irshaid, I., \& Al-Sumadi, A. (2011). Histological findings in women with postmenopausal bleeding: Jordanian figures. Eastern Mediterranean Health Journal, 17(7), 582-586.

19. Elkholi, D. G. E., \& Nagy, H. M. (2015). Unexplained postmenopausal uterine bleeding from atrophic endometrium: Histopathological and hormonal studies. Middle East Fertility Society Journal, 20(4), 262-270.

20. Srinivas, S., Maiti, S., \& Jothilakshmi, P. (2016). Management of proliferative endometrium on biopsy in post-menopausal women. J Gynecol Obstet, 4(6), 38-43.

21. Sobczuk, K., \& Sobczuk, A. (2017). New classification system of endometrial hyperplasia WHO 2014 and its clinical implications. Przeglad menopauzalny $=$ Menopause review, 16(3), 107111.

22. Ellenson, H., Ronnett, B. M., \& Kurman, R. J. (2010). Precursor lesions of endometrial carcinoma. In: Blaustein's Pathology of the Female Genital Tract. 6th ed., Springer, New York, 360-361.

23. Karakaya, B. K., Ozkan, N. T., Kansu-Celik, H., Coskun, B., Saridogan, E., \& Evliyaoglu, O. (2018). Malignancy risk of endometrial polyps among geriatric women. International Journal of Gerontology, 12(3), 215-217. 